\title{
PENGARUH TUTORIAL ONLINE TERHADAP NILAI AKHIR SEMESTER (KASUS MATAKULIAH MANAJEMEN STRATEGI DI UPBJJ-UT BATAM)
}

\author{
Albert Gamot Malau (albert@ut.ac.id) \\ UPBJJ-UT Batam \\ Herman (herman@ut.ac.id) \\ Pendidikan Matematika-FKIP UT
}

\begin{abstract}
This article discusses the influence of initiations materials, discussion and assignments in online tutorial to the final scores of Strategic Management course at Batam UT's regional center. There were at least $23 \%$ of respondents who stated their disagreement on each statement in the instrument. However, initiation materials, discussion and assignments were significantly influenced the final score. The three independent variables were able to explain $72,8 \%$ of variance in course's final score.
\end{abstract}

Keywords: assignment, discussion forum, initiation, online tutorial

\begin{abstract}
ABSTRAK
Artikel ini membahas pengaruh inisiasi, diskusi dan tugas pada tutorial online terhadap nilai akhir semester pada matakuliah Manajemen Strategi di UPBJJ-UT Batam. Terdapat paling sedikit 23\% responden menyatakan ketidak setujuan mereka sebagai jawaban terhadap pernyataan yang diberikan pada instrumen. Namun demikian, secara statistik, inisiasi, diskusi dan tugas mempengaruhi nilai akhir semester matakuliah secara signifikan. Ketiga variabel ini mampu menjelaskan varians pada nilai akhir semester sebesar 72,8\%.

Kata kunci: forum diskusi, inisiasi,tugas, tutorial online
\end{abstract}

Salah satu bentuk layanan kepada mahasiswa Universitas Terbuka (UT) adalah bantuan belajar dalam bentuk tutorial. Bantuan belajar tersebut umum dilaksanakan dalam pendidikan jarak jauh sebagaimana dikemukakan Holmberg (1995). Dijelaskan oleh Wardani, Andayani, Julaeha, Sugilar \& Arismanti (2002), tutorial sebagai sebuah bantuan belajar pada Pendidikan Jarak Jauh (PJJ) dapat diberikan dalam berbagai bentuk, misalnya: tatap muka, tertulis, online, radio, dan lainlain. Kegiatan tutorial melibatkan orang yang mengajar (tutor) dan orang yang belajar (tutee).

Tutorial online (tuton) diselenggarakan dengan memanfaatkan jaringan internet yang dapat diakses oleh mahasiswa dimanapun mereka berada. Bagi mahasiswa yang mengikuti tuton akan dibimbing oleh seorang tutor. Tutor berfungsi sebagai motivator,fasillitator dan sebagai mediator dalam proses pembelajaran. Nilai tuton berkontribusi 30\% terhadap nilai akhir semester (UT, 2012). Kontribusi nilai tuton terdiri dari angka partisipasi mahasiswa dan nilai tugas tutorial. Partisipasi dalam tutorial online dilihat dari keikutsertaan mahasiswa membuka materi inisiasi dan mengikuti forum diskusi. Kegiatan tutorial online dilakukan selama 9 minggu untuk 8 (delapan) inisiasi dan delapan kali forum diskusi. 
Menurut UT dalam angka, jumlah mahasiswa Universitas Terbuka pada tahun 2011 adalah 578.698 mahasiswa. 128325 diantaranya adalah mahasiswa non pendas. 57\% mahasiswa nonpendas mengikuti tuton. Mengingat konstribusi nilai tuton yang cukup besar (30\%), seharusnya tuton dapat membantu menaikkan tingkat kelulusan mahasiswa. Namun kenyataannya, tingkat kelulusan mahasiswa masih belum tinggi.

Artikel ini disusun dari hasil penelitian dengan tujuan menjelaskan Pengaruh tuton yang mencakup Inisiasi, forum diskusi dan tugas terhadap nilai akhir semester. Sampel yang digunakan adalah pada Matakuliah Manajemen Strategi EKMA4414 di UPBJJ-UT Batam. Secara lebih khusus tujuan diperinci sebagai berikut..

1. menjelaskan kesesuaian antara materi inisiasi dengan standar penulisan atau format tuton UT. 2. menjelaskan kesesuaian materi sajian dengan forum diskusi

3. menjelaskan kesesuaian tugas.

\section{METODOLOGI}

Analisis yang di gunakan adalah regresi linear berganda. Teknik pemilihan sampel dilakukan dengan cara purposive. Penentuan besarnya ukuran sampel mengunakan rumus Slovin

$$
n=\frac{N}{1+N(0,1)^{2}}
$$

dimana:

$\mathrm{N} \quad=$ jumlah populasi

$\mathrm{n} \quad=$ jumlah sampel

$0,1=$ toleransi kesalahan

Seluruh variabel bebas diukur dengan menggunakan skala 4 (TS=Tidak Setuju, KS=Kurang Setuju, S=Setuju, SS=Sangat Setuju). Populasi pada artikel ini adalah mahasiswa yang melakukan registrasi tutorial online untuk matakuliah Manajemen Strategi (EKMA4414). Sampel yang diambil berukuran 50 .

Untuk mendiskripsikan data penelitian digunakan statistik deskriptif, sedangkan untuk mengetahui pengaruh variabel bebas terhadap varibel terikat digunakan analisis regresi liner berganda dengan mengunakan bantuan SPSS. Sebelum melakukan analisis regresi terlebih dahulu dilakukan pengujian normalitas data, dan pengujian multikolinieritas.

Model persamaan regresi linier berganda dalam penelitian adalah sebagai berikut:

$$
y_{i}=a_{0}+a_{1} x_{1}+a_{2} x_{2}+a_{3} x_{3}+e_{i}
$$

dengan:

$y_{i} \quad=$ nilai akhir semester

$x_{1} \quad=$ inisiasi

$x_{2} \quad=$ forum diskusi

$x_{2} \quad=$ tugas

$a_{0} \quad=$ kostanta

$a_{1}-a_{3}=$ koefisien regresi 


\section{HASIL DAN PEMBAHASAN}

Instrumen penelitian sebelum diedarkan diujicobakan terlebih dahulu ke 30 orang mahasiswa. Nilai Cronbach alpha $>0,60$ dan semua pernyataan mempunyai nilai koefisien korelasi yang signifikan di $p<0,05$. Hal ini berarti bahwa instrumen penelitian cukup baik.

Secara deskriptif, berikut ini adalah respon dari peserta tuton terhadap pernyataanpernyataan yang diberikan. Ada 3 hal yang ditanyakan kepada responden yaitu tentang inisiasi, forum diskusi dan tugas.

\section{Inisiasi (X1)}

Indikator Inisiasi menanyakan tentang (1) kesesuaian antara BMP dengan materi inisiasi , (2) tampilan materi inisiasi, (3) Kemudahan bahasa yang digunakan. Berdasarkan hasil isian kuesioner diperoleh hasil sebagai berikut:

\begin{tabular}{llcrc}
\hline \multirow{2}{*}{ Pernyataan } & \multicolumn{5}{c}{$\%$} \\
\cline { 2 - 5 } & \multicolumn{1}{c}{ TS } & \multicolumn{1}{c}{ KS } & S & \multicolumn{1}{c}{ SS } \\
\hline Materi inisiasi sesuai dengan BMP & 10,18 & 15,57 & 8,98 & 65,27 \\
Tampilan materi inisiasi menarik & 46,56 & 0 & 10,21 & 43,23 \\
Bahasa yang digunakan mudah dimengerti & 37 & 0 & 23 & 40 \\
\hline Sumber:data yang diolah, 2011 & & &
\end{tabular}

Tampaknya inisiasi yang diberikan di tuton masih bermasalah karena lebih dari $25 \%$ responden menjawab tidak setuju atau kurang setuju terhadap ke tiga hal yang ditanyakan. Untuk itu UT harus mengingatkan para tutor agar menyempurnakan insiasi yang diberikan dengan mempertimbangkan ke tiga hal tersebut.

Para mahasiswa memang harus menguasai isi BMP. Karena itulah maka materi inisiasi pada tuton juga harus dapat membuat dan memaksa mahasiswa untuk mempelajari BMP. Penguasaan mahasiswa terhadap isi BMP akan tercermin dari hasil ujian yang mereka ikuti (Crocker \& Algina, 1986). Soal-soal ujian sudah tentu akan dikembangkan berdasarkan tujuan instruksional pada setiap matakuliah. Dengan demikian soal-soal ujian akan mencerminkan isi BMP.

Ada banyak studi tentang dampak dari tulisan yang menarik terhadap hasil bacaan yang diingat (Krapp, Hidi, \& Renninger, 1992). Banyak dari hasil-hasil studi yang melaporkan bahwa materi yang menarik akan lebih mudah diingat oleh pembaca (Wade \& Adams, 1990). Selain itu, tampilan yang jelas juga penting dibuat pada penyajian matakuliah (Shih \& Hung, 2007).

Ketertarikan adalah variabel motivasi yang unik. Ketertarikan dapat dilihat dari bertambahnya perhatian, dan konsentrasi (Hidi, 2006). Suatu penjelasan yang diberikan dengan cara yang berbeda tentunya juga akan mempunyai akibat yang berbeda pula . Misalnya suatu konsep yang dijelaskan dengan bahasa yang baik tentunya akan berbeda dampaknya bila penjelasan tersebut diberikan dengan bahasa yang kurang baik. Karena itu, pada inisiasi gunakanlah bahasa yang jelas, menarik tapi tidak bertele-tele. Selain itu, diharapkan materi inisiasi yang dikembangkan oleh para tutor harus dibuat demikian rupa sehingga mudah dimengerti, jelas dan dapat menarik perhatian mahasiswa. 


\section{Forum diskusi (X2)}

Indikator forum diskusi adalah tentang (1) kesesuaian sistematika forum diskusi dengan materi inisiasi, (2) kesesuaian format forum diskusi, (3) feedback dari tutor. Hasil isian responden adalah:

\begin{tabular}{lcccc}
\hline \multirow{2}{*}{ Pernyataan } & \multicolumn{4}{c}{$\%$} \\
\cline { 2 - 5 } & TS & KS & S & SS \\
\hline Materi Diskusi sesuai dengan materi inisiasi & 36 & 0 & 10 & 54 \\
Forum diskusi sesuai format & 55 & 0 & 5 & 40 \\
Tutor memberikan umpan balik & 58 & 0 & 12 & 30 \\
\hline Sumber:data yang diolah,2011 & \multicolumn{4}{c}{}
\end{tabular}

Hasil jawaban responden belum menunjukkan bahwa forum diskusi yang ditawarkan pada tuton sudah memenuhi kebutuhan mahasiswa. Hal ini tampak dari tingginya pilihan mahasiswa yang menyatakan ketidak setujuan terhadap format forum diskusi dan umpan balik dari tutor. Untuk itu institusi perlu melakukan evaluasi terhadap penyelengaraan tutorial online terutama pada forum diskusi.

Bila materi diskusi yang diberikan sesuai dengan materi inisiasi maka mahasiswa tentunya akan lebih mudah mengikutinya. Selain itu, hasil diskusi akan menambah pemahaman mahasiswa terhadap isi BMP. Hasilnya sudah tentu akan terlihat dari nilai ujian mereka (Crocker \& Algina, 1986).

Umpan balik harus diberikan kepada peserta didik. Hasil penelitian menunjukkan bahwa keterlibatan tutor akan berpengaruh terhadap aktifitas mahasiswa dalam mengikuti proses tutorial online (Chen, Gonyea, \& Kuh, 2008). Oleh karena itu, walaupun mahasiswa yang terlibat pada tuton cukup banyak, tutor harus tetap menyempatkan waktu untuk memberi umpan baik. Paling tidak setiap akhir diskusi, tutor dapat memberikan respon secara umum terhadap hasil diskusi mahasiswa.

\section{Tugas (X3)}

Indikator untuk pemberian tugas pada tuton adalah tentang (1) kesesuaian tugas dengan BMP, (2) kesesuaian pemberian tugas dengan jadwal yang sudah ditentukan, (3) pemahaman mahasiswa tentang tata cara pengiriman tugas, (4) pemahaman mahasiswa tentang tata cara penilaian tuton.

Tiga dari empat indikator yang ditanyakan ke peserta tuton menunjukkan bahwa lebih dari $46 \%$ responden menyatakan bahwa tugas yang diberikan tidak memenuhi harapan mereka. Hal ini harus menjadi peringatan bagi tutor bahwa mereka harus membuat tugas yang memang dapat membantu mahasiswa selain merespon jawaban tugas-tugas dengan benar.

\begin{tabular}{lcccc}
\hline \multirow{2}{*}{ Pernyataan } & \multicolumn{4}{c}{$\%$} \\
\cline { 2 - 5 } & TS & KS & S & SS \\
\hline Tugas yang diberikan sesuai degan BMP & 23 & 0 & 12 & 65 \\
Pemberian tugas sesuai jadwal & 48 & 0 & 22 & 30 \\
Mahasiswa memahami tata cara pengiriman tugas & 46 & 0 & 20 & 34 \\
Mahasiswa memahami tata cara penilaian tuton & 65 & 0 & 20 & 15 \\
\hline Sumber: Data diolah,2011 & & & &
\end{tabular}


Tugas yang diberikan memang seharusnya mendukung proses belajar mahasiswa sehingga membuat mahasiswa mengerjakan tugas-tugas dengan benar. Kalau semua ini berjalan seperti yang direncanakan dan mahasiswa juga terpacu untuk belajar maka mereka akan siap mengikuti ujian karena mereka memang sudah menguasai isi BMP. Hasil ujian akan mencerminkan penguasaan mereka terhadap isi materi yang dipelajari (Crocker \& Algina, 1986).

\section{Pengujian Hipotesis}

Dari hasil perhitungan diperoleh koefisien determinasi $\left(R^{2}\right)$ sebesar $72,8 \%$. Hal ini menunjukkan bahwa ke tiga variabel bebas yaitu insiasi, diskusi dan tugas dapat menjelaskan $72,8 \%$ varians yang ada pada variabel tak bebas nilai akhir semester (Tabel 1). Ini adalah hasil yang cukup besar. tapi mungkin bukan hal yang mengherankan karena nilai tutorial online berkontribusi sebesar $30 \%$ terhadap nilai akhir semester matakuliah.

Tabel 1. R, $\mathrm{R}^{2}$ dan Adjusted $\mathrm{R}^{2}$

\begin{tabular}{ccccc} 
Model & $\mathrm{R}$ & $R$ Square & $\begin{array}{l}\text { Adjusted } \\
R \text { Square }\end{array}$ & $\begin{array}{c}\text { Std. Error if } \\
\text { the Estimate }\end{array}$ \\
\hline 1 & $0,854^{a}$ & 0,728 & 0,721 & 0,68907 \\
\hline
\end{tabular}

Hasil uji hipotesa menunjukkan bahwa variabel bebas inisiasi, diskusi dan tugas secara bersama-sama berpengaruh secara signifikan terhadap nilai akhir semester $(F=50,713, p<0,001)$. Dari Tabel 2 tampak bahwa materi insiasi mempunyai sumbangan yang terbesar, disusul oleh kegiatan diskusi dan tugas-tugas yang diberikan. Persamaan regresi yang terbentuk adalah

$$
Y=2,839+0,560 X_{1}+0,284 X_{2}-0.164 X_{3}
$$

Tabel 2. Uji-t

\begin{tabular}{|c|c|c|c|c|c|}
\hline \multirow{2}{*}{ Model } & \multicolumn{2}{|c|}{ Unstandardized Coefficients } & \multirow{2}{*}{$\begin{array}{c}\text { Standardized } \\
\text { Coefficients } \\
\text { Beta }\end{array}$} & \multirow{2}{*}{$\mathrm{t}$} & \multirow{2}{*}{ Sig. } \\
\hline & B & Std Error & & & \\
\hline Constant & 2,839 & 0,659 & - & 4,308 & 0,000 \\
\hline$X_{1}$ & 0,560 & 0,079 & 0,575 & 7,105 & 0,000 \\
\hline$X_{2}$ & 0,284 & 0,072 & 0,319 & 3,934 & 0,000 \\
\hline$X_{3}$ & $-0,164$ & 0,065 & $-0,131$ & $-2,535$ & 0,013 \\
\hline
\end{tabular}

\section{Pengaruh Materi Inisiasi terhadap Nilai Akhir Semester}

Materi inisiasi memberi sumbangan yang terbesar karena tampaknya soal-soal ujian yang dikerjakan oleh peserta tuton sangat sesuai dengan materi yang diberikan pada inisiasi tuton. Memang materi inisiasi harus mencerminkan isi BMP. Temuan ini konsisten dengan pendapat mahasiswa yaitu sekitar 75\% responden menyatakan bahwa materi inisiasi sesuai dengan isi BMP. 


\section{Pengaruh Forum Diskusi terhadap Nilai Akhir Semester}

Nilai koefisien regresi terbesar ke dua adalah forum diskusi yaitu sebesar 0,284. Sumbangan forum diskusi terhadap nilai akhir matakuliah tampaknya juga cukup beralasan. Selama materi diskusi mendukung kemampuan mahasiswa menjawab soal-soal ujian maka mahasiswa akan merespon kegiatan tersebut secara positif. Hal ini juga tampak dari pendapat mahasiswa yaitu 64\% dari mereka menyatakan bahwa materi diskusi relevan dengan isi BMP.

\section{Pengaruh Tugas terhadap Nilai Akhir Semester}

Nilai koefisien regresi untuk tugas tutorial adalah -0,164. Hal ini tampaknya agak aneh karena tugas berkonstrusi negatif dan signinifikan terhadap nilai akhir semeseter. Tetapi temuan juga menyatakan bahwa sekitar 50\% mahasiswa menyatakan ketidaksetujuan mereka terhadap pernyataan yang diberikan pada kegiatan tugas-tugas tuton. Tampaknya memang ada masalah pada tugas-tugas yang diberikan pada tuton. Untuk itu, para tutor tuton perlu mencermati kembali tugastugas yang pernah mereka berikan.

Secara statistik angka negatif ini manyatakan bahwa semakin sukar tugas-tugas atau semakin kecil nilai tugas yang diperoleh mahasiswa maka semakin tinggi nilai akhir matakuliah yang diterima. Mungkin bagi mereka yang merasa memperoleh nilai kecil di kegiatan tuton akan belajar lebih keras agar memperoleh nilai ujian akhir matakuliah yang tinggi.

\section{KESIMPULAN}

1. Pada umumnya mahasiswa peserta menyatakan bahwa mereka setuju terhadap kesesuaian kegiatan tuton. Namun demikian pada tugas-tugas tuton mereka banyak mempermasalahkannya.

2. Ke tiga varibel bebas yaitu inisiasi, diskusi dan tugas berkontribusi secara signifikan terhadap nilai akhir matakuliah. Namun demikian, tugas-tugas tuton ternyata berkontribusi secara negatif terhadap nilai akhir matakuliah.

3. Perlu perbaikan terhadap inisiasi, diskusi dan tugas-tugas yang dianggap belum baik oleh mahasiswa peserta tuton.

\section{REFERENSI}

Chen, P., Gonyea, R., \& Kuh, G. (2008). Learning at a distance: Engaged or Not?. Journal of Online Education, 4(3). http://www.innovateonline.info/index.php?view=article\&id=438.

Crocker, L. \& Algina, J. (1986). Introduction to classical \& modern test theory. Florida: Holt, Rinehart and Winston, Inc.

Hidi, S. (2006). Interest: A unique motivational variable. Educational Research Review, 1(2), 69-82. Holmberg, B. (1995). Theory and practice of distance education. London: Routletge.

Krapp, A., Hidi, S. \& Renninger, K. A. (1992). Interest, learning and development. In A. Renninger, S. Hidi, and A. Krapp (Eds.), The role of interest in learning and development (pp. 3-25). Hillsdale, NJ: Erlbaum.

Shih. T.K. \& Hung. J.C. (2007). Future direction in distance learning and communication technologies. London: Information Science Publishing.

UT. (2012). Katalog Universitas Terbuka 2012. Jakarta: Universitas Terbuka.

UT dalam Angka 2011. http://www.ut.ac.id/tentang-ut/ut-dalam-angka.html

Wade, S. E., \& Adams, B. (1990). Effects of importance and interest on recall of biographical text. Journal of Reading Behavior, 22, 331-353. 
Wardani, I G.A.K., Andayani., Julaeha, S., Sugilar., \& Arismanti, Y. (2002). Kinerja guru lulusan program penyetaraan D-II PGSD guru kelas kurikulum 1996. Laporan penelitian. Pusat Penelitian Kelembagaan, Lembaga Penelitian Universitas Terbuka. 